\title{
PROPERTI EIGEN UNTUK GRAF $K$-REGULAR TAK TERHUBUNG
}

\author{
Respitawulan \\ Program Studi Matematika, Fakultas MIPA, Universitas Islam Bandung \\ respitawulan@unisba.ac.id
}

\begin{abstract}
One of the important properties of an adjacency matrix as a representation of a graph is its eigen property. According to Biggs, a $k$-regular connected graph will have $k$ as one of its Eigen value and the multiplicity is 1 . Here, we investigate the Eigen value and its multiplicity of a non-connected $k$-regular graph. The result shows if a non-connected $k$-regular graph has $c$ components, then $k$ will be one of its eigen value with the geometric multiplicity of $c$.
\end{abstract}

Keywords: adjacency matrix, eigen values, geometric multiplicity

Abstrak. Salah satu sifat penting dari matriks adjasen sebagai representasi dari graf adalah sifat eigennya. Biggs menyatakan bahwa graf regular terhubung dengan derajat $k$ akan memiliki nilai eigen $k$ yang multiplisitasnya satu. Di sini diselidiki nilai eigen untuk graf $k$-regular yang tak terhubung. Jika graf $k$-regular tak terhubung memiliki $c$ buah komponen, maka $k$ akan menjadi salah satu nilai eigen graf tersebut dengan multiplisitas geometri $c$.

Kata kunci: matriks adjasen, nilai eigen, multiplisitas geometri

\section{Pendahuluan}

Salah satu sifat dari matriks adjasen Graf yang biasanya perlu diselidiki adalah sifat eigennya, termasuk nilai eigen, vektor eigen dan multiplisitas dari nilai eigen. Nilai eigen dari graf telah diaplikasikan di berbagai bidang, misalnya teori informasi [2], kimia quantum [3], studi geografis [5] dan ilmu sosial [4]. Biggs [1] menyatakan bahwa $k$ adalah salah satu nilai eigen untuk graf $\mathrm{k}$-regular. Jika graf tersebut terhubung, maka multiplisitas geometri dari $k$ adalah satu. Namun, Biggs tidak menjelaskan bagaimana multiplisitas nilai eigen untuk graf $k$-regular yang tak terhubung. Karenanya, perlu diselidiki bagaimana multiplisitas nilai eigen $k$ pada graf $k$-regular yang tak terhubung dengan $n$ buah komponen.

\section{Spektrum dari Graf}

Salah satu bentuk representasi dari graf adalah matriks adjasennya. Berikut ini diberikan definisi dan beberapa teorema yang berkaitan dengan sifat matriks adjasen.

\section{Definisi 2.1: (Matriks Adjasen)}

Matriks adjasen (adjacency matrix) dari graf $\Gamma$ dengan verteks-verteks $V_{1}, \ldots, V_{n}$ adalah matriks $A=A(\Gamma)$, berukuran $n \times n$ atas lapangan kompleks, yang unsur-unsurnya $a_{i j}$ adalah:

$$
a_{i j}=\left\{\begin{array}{lc}
1, & \text { jika } V_{i}, V_{j} \text { bertetangga } \\
0, & \text { lainnya }
\end{array}\right.
$$

Dari definisi, dapat terlihat bahwa matriks $A$ adalah matriks real yang simetris dan $\operatorname{tr}(A)=0$.

\section{Definisi 2.2: (Spektrum Graf)}

Spektrum dari graf $\Gamma$ adalah himpunan bilangan yang merupakan nilai eigen dari $A(\Gamma)$ bersama dengan multiplisitasnya sebagai nilai eigen $A(\Gamma)$. Jika nilai-nilai eigen yang berbeda dari $A$ adalah $\lambda_{0}>\lambda_{1}>\cdots>$ $\lambda_{s-1}$ dan multiplisitas nilai eigen tersebut masing-masing adalah $m\left(\lambda_{0}\right), m\left(\lambda_{1}\right), \cdots, m\left(\lambda_{s-1}\right)$, maka spektrumnya dapat dituliskan sebagai 


$$
\operatorname{Spec} \Gamma=\left(\begin{array}{cccc}
\lambda_{0} & \lambda_{1} & \cdots & \lambda_{s-1} \\
m\left(\lambda_{0}\right) & m\left(\lambda_{1}\right) & \cdots & m\left(\lambda_{s-1}\right)
\end{array}\right)
$$

\section{Contoh 1}

Misalkan graf lengkap $K_{n}$ adalah graf yang memiliki $n$ verteks dan setiap pasang verteksnya adjasen [6] sehingga graf $K_{4}$ akan memiliki matriks adjasen

$$
A=\left[\begin{array}{llll}
0 & 1 & 1 & 1 \\
1 & 0 & 1 & 1 \\
1 & 1 & 0 & 1 \\
1 & 1 & 1 & 0
\end{array}\right]
$$

Dari hasil perhitungan, nilai-nilai eigen dari $K_{4}$ adalah 3 dan -1 dengan multiplisitas masing-masing adalah 1 dan 3 sehingga didapat

$$
\operatorname{Spec}(\Gamma)=\left(\begin{array}{rr}
3 & -1 \\
1 & 3
\end{array}\right)
$$

Graf $K_{4}$ dengan verteks-verteks $V_{1}, V_{2}, V_{3}$ dan $V_{4}$ dapat digambarkan sebagai berikut.

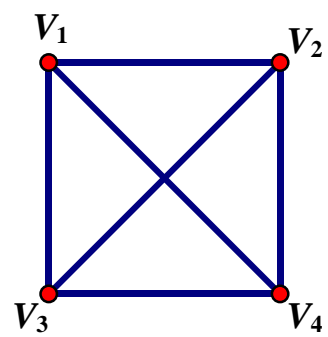

Gambar 1. Graf $K_{4}$

Pada Gambar 1, terlihat bahwa masing-masing verteks dari $K_{4}$ terhubung dengan 3 verteks lainnya atau memiliki 3 edge. Graf $K_{4}$ ini disebut sebagai graf regular dengan derajat atau valensi 3. Secara umum, pada graf regular dengan derajat $k$, terdapat beberapa sifat khusus untuk sifat eigen pada matriks adjasen yang merepresentasikan graf tersebut [1].

\section{Teorema 2.3}

Misalkan $\Gamma$ adalah graf regular dengan derajat $k$, pernyataan berikut berlaku:

(1) $k$ adalah nilai eigen dari $\Gamma$;

(2) Jika $\Gamma$ terhubung, multiplisitas geometri dari $k$ adalah 1;

(3) Untuk setiap nilai eigen $\lambda$ dari $\Gamma$, berlaku $|\lambda| \leq k$.

Graf regular terhubung memiliki tambahan sifat berikut.

\section{Teorema 2.4}

Misalkan J adalah matriks $n \times n$ yang unsur-unsurnya adalah 1. Jika A adalah matriks adjasen dari graf regular dengan $n$ verteks dan valensi $k$, maka

$$
A J=J A=k J
$$

Dari definisi dan teorema yang telah disebutkan, akan diselidiki nilai eigen dan multiplisitas geometri untuk graf regular tak terhubung. 


\section{Nilai Eigen dan Multiplisitas Geometri Graf Regular Tak Terhubung}

Sebelum membahas tentang graf $k$-regular tak terhubung, akan diperlihatkan bentuk vektor eigen yang bersesuaian dengan nilai eigen $k$ pada graf $k$-regular. Vektor eigen ini didapat sebagai akibat dari Teorema 2.3 poin (2) dan Teorema 2.4 .

\section{Akibat 3.1}

Misalkan $\Gamma$ adalah graf regular terhubung dengan derajat $k$, maka vektor

$$
\boldsymbol{u}=\left[\begin{array}{c}
1 \\
1 \\
\vdots \\
1
\end{array}\right]
$$

adalah vektor eigen tunggal yang berkaitan dengan nilai eigen $k .^{1}$

Bukti.

Misalkan

$$
A \boldsymbol{u}=\left[\begin{array}{c}
(A \boldsymbol{u})_{1} \\
(A \boldsymbol{u})_{2} \\
\vdots \\
(A \boldsymbol{u})_{n}
\end{array}\right]
$$

Untuk setiap $1 \leq i \leq n$, nilai $(A \boldsymbol{u})_{i}$ akan sama dengan banyaknya titik di $\Gamma$ yang bertetangga dengan titik $v_{i}$. Karena $\Gamma$ adalah $k$-regular, maka $(A \boldsymbol{u})_{i}=k$ untuk setiap $i$. Akibatnya,

$$
A \boldsymbol{u}=\left[\begin{array}{c}
(A u)_{1} \\
(A u)_{2} \\
\vdots \\
(A u)_{n}
\end{array}\right]=\left[\begin{array}{c}
k \\
k \\
\vdots \\
k
\end{array}\right]=k\left[\begin{array}{c}
1 \\
1 \\
\vdots \\
1
\end{array}\right]=k \boldsymbol{u}
$$

Jadi, terbukti bahwa

$$
\boldsymbol{u}=\left[\begin{array}{c}
1 \\
1 \\
\vdots \\
1
\end{array}\right]
$$

adalah vektor eigen dari $\Gamma$ yang bersesuaian dengan nilai eigen $k$.

Selanjutnya, andai ada vektor eigen lain yang bersesuaian dengan $k$ dan bukan kelipatan dari $\boldsymbol{u}$, berarti $k$ bersesuaian dengan lebih dari 1 vektor eigen yang berbeda. Hal ini bertentangan dengan Teorema 1 poin 2 menyatakan multiplisitas geometri $k$ adalah 1 sehingga pembangun dari ruang eigen yang bersesuaian dengan $k$ hanya terdiri atas satu unsur. Jadi, haruslah $\boldsymbol{u}$ adalah satu-satunya vektor eigen dari $\Gamma$ untuk nilai eigen $k$.

\section{Contoh 2}

Pandanglah Graf $\Gamma_{1}$ yang merupakan graf 4-regular dengan 6 titik seperti diperlihatkan di Gambar 2. Matriks adjasennya adalah

$$
A_{1}=\left[\begin{array}{llllll}
0 & 1 & 1 & 0 & 1 & 1 \\
1 & 0 & 0 & 1 & 1 & 1 \\
1 & 0 & 0 & 1 & 1 & 1 \\
0 & 1 & 1 & 0 & 1 & 1 \\
1 & 1 & 1 & 1 & 0 & 0 \\
1 & 1 & 1 & 1 & 0 & 0
\end{array}\right]
$$

\footnotetext{
${ }^{1}$ Ketunggalan di sini mengacu pada pembangun ruang eigen dari matriks adjasennya, yang berkaitan dengan nilai eigen $\mathrm{k}$. Dengan kata lain, meskipun kombinasi linier dari vektor eigen tersebut juga merupakan vektor eigen, ketunggalannya tetap berlaku.
} 


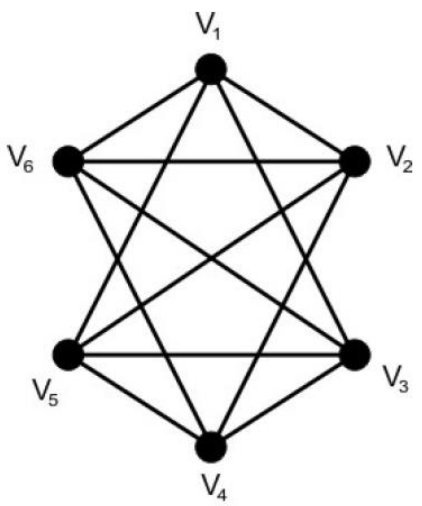

Graf $\Gamma_{1}$

Gambar 2. $\Gamma_{1}$ graf 4-regular terhubung dengan 6 titik

Dari hasil perhitungan, didapat

$$
\operatorname{Spec}\left(A_{1}\right)=\left(\begin{array}{ccc}
0 & -2 & 4 \\
3 & 2 & 1
\end{array}\right)
$$

Vektor eigen yang bersesuaian dengan nilai eigen 0 adalah

$$
\left[\begin{array}{c}
0 \\
0 \\
0 \\
0 \\
-1 \\
1
\end{array}\right],\left[\begin{array}{c}
-1 \\
0 \\
0 \\
1 \\
0 \\
0
\end{array}\right] \text { dan }\left[\begin{array}{c}
0 \\
-1 \\
1 \\
0 \\
0 \\
0
\end{array}\right]
$$

vektor eigen yang bersesuaian dengan nilai eigen -2 adalah

$$
\left[\begin{array}{c}
0 \\
-1 \\
-1 \\
0 \\
1 \\
1
\end{array}\right] \text { dan }\left[\begin{array}{c}
1 \\
-1 \\
-1 \\
1 \\
0 \\
0
\end{array}\right]
$$

dan vektor eigen yang bersesuaian dengan nilai eigen 4 adalah

$$
\left[\begin{array}{l}
1 \\
1 \\
1 \\
1 \\
1 \\
1
\end{array}\right]
$$

\section{Teorema 3.2}

Misalkan $\Gamma$ adalah graf regular dengan derajat $k$, maka multiplisitas geometri dari $k$ sama dengan banyaknya komponen dari $\Gamma$.

Bukti. Misalkan $\Gamma$ memiliki $n$ titik dan $c$ komponen. Dengan melakukan pelabelan yang sesuai, kita dapat menuliskan matriks adjasen A dalam bentuk blok matriks yang berbentuk

$$
A=\left[\begin{array}{ccc}
A_{1} & 0 & 0 \\
0 & \ddots & 0 \\
0 & 0 & A_{c}
\end{array}\right] .
$$


Misalkan $n_{i}$ menyatakan banyaknya titik pada komponen ke-i dari $\Gamma$. Perhatikan bahwa masing-masing blok berbentuk matriks $k$-regular yang terhubung. Karenanya, dari Akibat 3.1, akan didapat $\boldsymbol{u}_{1}, \boldsymbol{u}_{2}, \cdots, \boldsymbol{u}_{\boldsymbol{n}}$ vektor-vektor kolom yang semua unsurnya bernilai 1 dan panjangnya masing-masing $n_{1}, n_{2}, \cdots n_{c}$.

Selanjutnya, masing-masing $\boldsymbol{u}_{\boldsymbol{i}}$ 'diperpanjang' dengan menambahkan unsur 0 sebanyak $n-n_{i}$ yang letaknya disesuaikan dengan posisi blok $A_{i}$, yaitu dengan unsur 0 yang di bagian atas sebanyak $n_{1}+\cdots+$ $n_{i-1}$ dan unsur 0 yang di bagian bawah sebanyak $n_{i+1}+\cdots+n_{c}$. Akan ditunjukkan bahwa $\boldsymbol{v}_{i}$ adalah vektor eigen untuk nilai eigen $k$, yakni memenuhi $A \boldsymbol{v}_{i}=k \boldsymbol{v}_{i}$.

$$
A \boldsymbol{v}_{\boldsymbol{i}}=\left[\begin{array}{cccccc}
A_{1} & 0 & \ldots & & 0 & 0 \\
0 & A_{2} & 0 & \ldots & & 0 \\
& 0 & \ddots & 0 & & \vdots \\
\vdots & & 0 & A_{i} & 0 & \\
0 & & & 0 & \ddots & 0 \\
0 & 0 & \ldots & & 0 & A_{c}
\end{array}\right]\left[\begin{array}{c}
0 \\
\vdots \\
0 \\
\boldsymbol{u}_{\boldsymbol{i}} \\
0 \\
\vdots \\
0
\end{array}\right]=\left[\begin{array}{c}
0 \\
\vdots \\
0 \\
A_{i} \boldsymbol{u}_{i} \\
0 \\
\vdots \\
0
\end{array}\right]=\left[\begin{array}{c}
0 \\
\vdots \\
0 \\
k \boldsymbol{u}_{i} \\
0 \\
\vdots \\
0
\end{array}\right]=k\left[\begin{array}{c}
0 \\
\vdots \\
0 \\
\boldsymbol{u}_{i} \\
0 \\
\vdots \\
0
\end{array}\right]=k \boldsymbol{v}_{i}
$$

Jadi $\boldsymbol{v}_{i}$ adalah vektor eigen untuk nilai eigen $k$. Perhatikan bahwa untuk setiap $i \neq j$, jika $n_{i}=n_{j}$, maka $\boldsymbol{u}_{\boldsymbol{i}}=\boldsymbol{u}_{\boldsymbol{j}}$ pula, tetapi perbedaan posisi blok $A_{i}$ dan $A_{j}$ akan menyebabkan posisi unsur-unsur nol di $\boldsymbol{v}_{\boldsymbol{i}}$ dan $\boldsymbol{v}_{\boldsymbol{j}}$ berbeda sehingga pasti $\boldsymbol{v}_{\boldsymbol{i}} \neq \boldsymbol{v}_{\boldsymbol{j}}$. Karena setiap komponen graf menyumbangkan tepat satu vektor yang dapat diperpanjang menjadi vektor eigen dari A yang bersesuaian dengan nilai eigen $k$, multiplisitas dari $k$ akan sama dengan banyaknya komponen $\Gamma$.

Vektor $\boldsymbol{u}=\left[\begin{array}{c}1 \\ \vdots \\ 1\end{array}\right]$ yang disebutkan pada Akibat 3.1, masih memenuhi persamaan $A \boldsymbol{u}=k \boldsymbol{u}$ karena $\boldsymbol{u}=\boldsymbol{v}_{\mathbf{1}}+$ $v_{2}+\cdots+v_{c}$ adalah unsur dari ruang eigen $A$ yang bersesuaian dengan nilai eigen $k$. Namun, tentu saja, vektor $\boldsymbol{u}$ tidak menjadi satu-satunya vektor eigen untuk $k$.

Untuk mengillustrasikan Teorema 3.2, dapat dilihat contoh berikut.

\section{Contoh 3}

Pandanglah graf $\Gamma_{2}$ seperti yang ditunjukkan pada Gambar 3. Graf $\Gamma_{2}$ ini adalah matriks 2-regular yang tak terhubung dengan 7 titik dan 2 komponen. Matriks ketetanggaannya adalah

$$
A_{2}=\left[\begin{array}{lllllll}
0 & 1 & 1 & 0 & 0 & 0 & 0 \\
1 & 0 & 1 & 0 & 0 & 0 & 0 \\
1 & 1 & 0 & 0 & 0 & 0 & 0 \\
0 & 0 & 0 & 0 & 1 & 0 & 1 \\
0 & 0 & 0 & 1 & 0 & 1 & 0 \\
0 & 0 & 0 & 0 & 1 & 0 & 1 \\
0 & 0 & 0 & 1 & 0 & 1 & 0
\end{array}\right]
$$

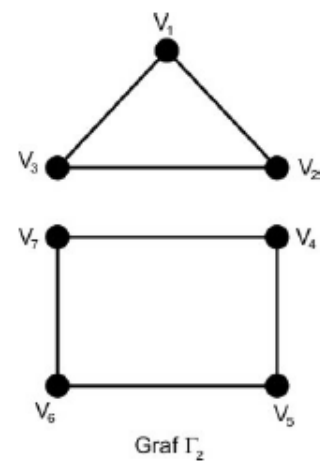

Gambar $3 \Gamma_{2}$ graf 2-regular tak terhubung

Vektor-vektor eigen yang bersesuaian dengan nilai eigen $k=2$ adalah

$$
\boldsymbol{v}_{1}=\left[\begin{array}{l}
1 \\
1 \\
1 \\
0 \\
0 \\
0 \\
0
\end{array}\right] \text { dan } \boldsymbol{v}_{2}=\left[\begin{array}{l}
0 \\
0 \\
0 \\
1 \\
1 \\
1 \\
1
\end{array}\right]
$$

\footnotetext{
${ }^{1}$ Ketunggalan di sini mengacu pada pembangun ruang eigen dari matriks adjasennya, yang berkaitan dengan nilai eigen $\mathrm{k}$. Dengan kata lain, meskipun kombinasi linier dari vektor eigen tersebut juga merupakan vektor eigen, ketunggalannya tetap berlaku.
} 
Karena $\boldsymbol{u}=\boldsymbol{v}_{1}+\boldsymbol{v}_{2}$, akan didapat

$$
A \boldsymbol{u}=A\left(\boldsymbol{v}_{1}+\boldsymbol{v}_{2}\right)=A \boldsymbol{v}_{1}+A \boldsymbol{v}_{2}=k \boldsymbol{v}_{1}+k v_{2}=k\left(\boldsymbol{v}_{1}+v_{2}\right)=k \boldsymbol{u}
$$

Jadi, $\boldsymbol{u}$ juga adalah vektor eigen yang bersesuaian dengan nilai eigen $k$.

\section{Kesimpulan}

Untuk setiap $\Gamma$ graf regular derajat $k$, vektor

$$
\boldsymbol{u}=\left[\begin{array}{c}
1 \\
1 \\
\vdots \\
1
\end{array}\right]
$$

akan selalu menjadi vektor eigen dari matriks adjasen $A(\Gamma)$ yang bersesuaian dengan nilai eigen $k$. Pada graf regular terhubung, nilai eigen $k$ memiliki multiplisitas 1 . Sedangkan, pada graf regular tak terhubung dengan $c$ komponen, nilai eigen $k$ akan memiliki multiplisitas geometri $c$ dan vektor $\boldsymbol{u}$ akan menjadi hasil kombinasi linear dari $c$ buah vektor eigen yang bersesuaian dengan nilai eigen $k$.

\section{Referensi}

[1] Biggs, N. (1974). Algebraic Graph Theory. London: Cambridge Univ. Press

[2] Cohn, M. (1995). On the channel capacity of read/write isolated memory. Discrete Math., Vol. 56, pp. 1-8.

[3] Cvetkovic, D. M., Doob, M., and Sachs, H. (1995). Spectra of Graphs, Third Edition. Johann Ambrosius Barth Verlag.

[4] Roberts, F. (1987). Graph Theory and Its Applications to Problems of Society, SIAM.

[5] Tinkler, K. (1972). The physical interpretation of eigenvalues of dichotomous matrix. Inst. Brit. Geogr. Puli., Vol. 55, pp. $17-46$

[6] Wilf, H. S. (1967). The Eigenvalues of A Graph and Its Chromatic Number, J. London Math. Soc. Vol. 42, pp. 330332. 